\title{
An Approach to the Diastereoselective Synthesis of Cyclohexane-1,3-dicarboxamide Derivatives via a Pseudo Five-Component -Reaction Based on Diketene
}

\author{
Bahareh Talaei, Majid M.Heravi, Hossein Oskooie, Atieh Rezvanian
}

Physics and Chemistry Faculty, Alzahra University Vanak, Tehran, Iran

\begin{abstract}
A one-pot pseudo five-component reaction for the synthesis of 2-aryl-4hydroxy-4-methyl-6-oxo-N $\quad$ 1,N $\quad 3$-dialkylcyclohexane-1,3-dicarboxamide derivatives involving different primary amines, various aromatic aldehydes, and diketene in the presence of triethylamine with high yields is achieved.
\end{abstract}

Keywords: diketene, cyclohexanone, multicomponent reaction, one-pot reaction, diastereoselective synthesis 